\title{
Characterization of the Conjugation System Associated with the Staphylococcus aureus Plasmid pJE1
}

\author{
By JANE EVANS† AND K. G. H. DYKE* \\ Microbiology Unit, Department of Biochemistry, University of Oxford, South Parks Road, \\ Oxford OXI $3 Q U, U K$
}

(Received 13 February 1987; revised 7 August 1987)

\begin{abstract}
The conjugation system of Staphylococcus aureus that is conferred, at least in part, by plasmid pJE1, requires cell-to-cell contact. Optimum transfer was found when the numbers of donor and recipient cells were equal. Certain antibiotics increased the conjugation frequency. Fragments of plasmid pJE1 were cloned into a staphylococcal plasmid vector; although separate clones were isolated that conferred ethidium bromide resistance and gentamicin resistance, none of the clones carried the ability to conjugate. Transposon mutagenesis with $\mathrm{Tn} 551$ was used to create 26 mutants of pJE1. These were analysed for the position of the insertion and for their ability to conjugate. The sites of insertion were non-random. Only six mutants were unaffected in their conjugability; one showed increased ability to conjugate whilst the rest were either unable to conjugate or showed a reduced frequency. It is concluded that there are at least two separate regions necessary for conjugation and that the system is not obviously similar to that reported in streptococci.
\end{abstract}

\section{INTRODUCTION}

There is now evidence for conjugation between Staphylococcus aureus strains. Archer \& Johnston (1983), Forbes \& Schaberg (1983) and McDonnell et al. (1983) concluded that there is a conjugation-like transfer system since cell-to-cell contact is an absolute requirement. The process is energy dependent and requires viable donor cells, is resistant to DNAase, has no calcium requirement and transfer can occur between non-lysogenic donor and recipient cells. The Staph. aureus strains known to conjugate contain plasmids conferring gentamicin resistance on their hosts and it is therefore probable that the conjugation system is at least partly specified by genes present on these plasmids. Lacey (1980) provided evidence for a type of spontaneous transfer in mixed culture, distinct from both conventional transduction and conjugation. $\mathrm{He}$ describes this process as 'phage-mediated conjugation' since transfer requires direct cell-to-cell contact as well as the presence of lysogenic transducing phage in either the donor or the recipient. The precise mechanism of this 'phage-mediated conjugation' remains obscure as does the mechanism for transfer by conjugation. This latter system is certainly distinct from the typical system in Escherichia coli $\mathrm{K} 12$ since, for example, no evidence has been found for sex pili.

It has been shown that the broad host-range plasmids such as pAM-1 from Streptococcus faecalis can be transferred to Staph. aureus via filter membrane conjugation experiments (Engel et al., 1980; Schaberg et al., 1982), and then either back to Strep. faecalis or to a second Staph. aureus strain (Schaberg et al., 1982). There is no evidence that plasmids that confer responsiveness to sex pheromones can be transferred in the same way, although the pheromone cAM373 to which Strep. faecalis RC73(pAM373) responds has been detected in 23 Staph. aureus strains (Clewell et al., 1985). A similar type of pheromone system may therefore exist in the staphylococci.

† Present address: Malaghan Institute of Medical Research, Wellington Clinical School of Medicine, Wellington Hospital, Wellington 2, New Zealand. 
In this survey, investigations were focussed on the self-transmissible gentamicin-resistanceconferring plasmid pJE1. The strain used was Staph. aureus 8325 (pJE1), constructed by transfer of the $\mathrm{Gm}^{\mathrm{R}}$ plasmid from Staph. aureus A118 to $8325 \mathrm{~N}$ (Naidoo et al., 1983). The plasmid pJE1 $(50 \mathrm{kbp})$ has been mapped with respect to eight restriction enzymes and is known to confer resistance to ethidium bromide (Evans, 1986). By varying the conditions of the basic method, the mechanism by which conjugal transfer occurs was investigated. Restriction fragments were cloned in an attempt to localize the region involved in transfer. To define the pJEl-encoded conjugal genes, mutant derivatives of the plasmid were constructed by transposon mutagenesis with Tn551. Comparative physical analysis between the wild-type plasmid and the mutant derivatives allowed the location of regions involved in transfer.

\section{METHODS}

Bacterial strains and plasmids. The donor strain was Staphylococcus aureus 8325(pJE1). This was constructed by transfer of a gentamicin-resistance-conferring plasmid from Staph. aureus A118 (Naidoo et al., 1983) into Staph.

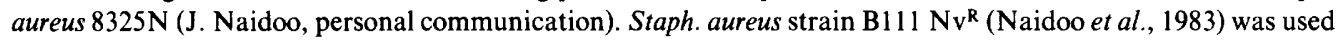
as recipient.

The Staph. aureus plasmid vector pCW59 (Wilson et al., 1981) was used in cloning experiments. It carries determinants for resistance to tetracycline and chloramphenicol, with a $B g l \mathrm{II}$ site within the latter determinant.

Transposon Tn551 (Khan \& Novick, 1980) was derived from Staph. aureus PS80::Tn551(p19789, Seg-1 $\Delta$ A) revertant E no. 17 (Browne, 1985).

Media and reagents. Brain heart infusion (BHI) broth (Oxoid) was used for growth of cultures in liquid. BHI solidified with $1.5 \%(\mathrm{w} / \mathrm{v})$ agar was used as solid medium, supplemented as appropriate with chloramphenicol $\left(20 \mu \mathrm{g} \mathrm{ml}^{-1}\right)$, erythromycin $\left(10 \mu \mathrm{g} \mathrm{m}^{-1}\right)$, gentamicin sulphate $\left(20 \mu \mathrm{g} \mathrm{ml}^{-1}\right)$ or novobiocin $\left(5 \mu \mathrm{g} \mathrm{ml}^{-1}\right)$. Growth was at $37^{\circ} \mathrm{C}$ under aerobic conditions unless otherwise stated.

Restriction enzymes were from Amersham, Bethesda Research Laboratories or New England Biolabs, and were used according to the manufacturers' instructions. DNA ligase (from bacteriophage T4) was obtained from Sigma.

Preparation of plasmid DNA and recombinant DNA techniques. The method of Novick \& Bouanchaud (1971) was used to purify plasmid DNA from Staph. aureus for cloning, transformation and restriction endonuclease analysis.

Transformation of Staph. aureus $8325 \mathrm{~N}$ protoplasts was as described by Lindberg (1981).

Conjugation. The procedure was based on that of Forbes \& Schaberg (1983). Donor bacteria, grown overnight on BHI agar plus gentamicin, and recipient bacteria, grown overnight on BHI agar plus novobiocin, were scraped off separately, resuspended in $\mathrm{BHI}$ medium containing $0.01 \mathrm{M}-\mathrm{CaCl}_{2}$ and the $\mathrm{OD}_{675}$ adjusted to 2.5. Two ml of each suspension were mixed and collected together by filtration through a $2.5 \mathrm{~cm}$ diameter, $0.45 \mu \mathrm{m}$ pore size nitrocellulose filter (Millipore). The filter was immediately placed on BHI agar with the bacteria touching the agar surface. After incubation for $16 \mathrm{~h}$ at $37^{\circ} \mathrm{C}$, each filter was transferred to $10 \mathrm{ml} 0.9 \%(\mathrm{w} / \mathrm{v})$ saline and thoroughly shaken. Samples $(0.15 \mathrm{ml})$ of the suspension were plated on BHI agar containing $20 \mu \mathrm{g}$ gentamicin ml $\mathrm{m}^{-1}$ and $5 \mu \mathrm{g}$ novobiocin $\mathrm{ml}^{-1}$. Colonies were counted after incubation at $37^{\circ} \mathrm{C}$ for $16 \mathrm{~h}$. Control plates, spread with $0 \cdot 15 \mathrm{ml}$ of either donor or recipient cells, were also incubated. The conjugation frequency is expressed as the number of transconjugant colonies per recipient in the original mixture.

Construction of mutants by transposition. Plasmid DNA was prepared from Staph. aureus PS80d : :Tn551(pI9789 Seg-1, $\Delta \mathrm{A}$ ) revertant $\mathrm{E}$ no. 17, a strain known to carry $\mathrm{Tn} 551$ (which confers resistance to erythromycin) on a plasmid that is temperature sensitive for replication (Browne, 1985). The DNA was used to transform Staph. aureus $8325(\mathrm{pJE} 1)$ to erythromycin resistance. Colonies that were both gentamicin resistant and erythromycin resistant, and therefore presumed to harbour both plasmids, were mixed and grown at $42{ }^{\circ} \mathrm{C}$ (a temperature at which the pI9789 plasmid derivative carrying Tn55I will not replicate). The culture was diluted 100 -fold into fresh BHI medium containing $20 \mu \mathrm{g}$ gentamicin $\mathrm{ml}^{-1}$ and $10 \mu \mathrm{g}$ erythromycin $\mathrm{ml}^{-1}$ and growth continued at $42^{\circ} \mathrm{C}$ for $5 \mathrm{~h}$. This culture was then diluted as before and the cycle of growth and dilution repeated a further four times. The growth at $42^{\circ} \mathrm{C}$ in the selective medium will select those bacteria in which $\mathrm{Tn} 551$ has transposed either to the pJE1 plasmid or to the chromosome. Plasmid DNA was prepared from the culture and used to transform Staph. aureus $8325 \mathrm{~N}$ to erythromycin resistance. Twenty-six transformants that were also resistant to gentamicin were chosen for further investigation.

Electrophoresis. Plasmid DNA and restriction-enzyme-digested DNA were electrophoresed through vertical gels of $1 \%(\mathrm{w} / \mathrm{v})$ agarose in TBE buffer $(500 \mathrm{~mm}$-Tris, $500 \mathrm{~mm}$-boric acid, $100 \mathrm{~mm}$-EDTA) containing $500 \mu \mathrm{g}$ ethidium bromide $\mathrm{l}^{-1}$. The DNA bands were visualized on a UV transilluminator and photographed.

Restriction-enzyme-digested fragments were isolated by electrophoretic elution onto DEAE-cellulose paper (Dretzen et al., 1981). 
Table 1. Conjugation frequencies after the addition of antibiotics to the filter incubation plates

Medium upon which filter was incubated

BHI agar only

BHI agar + chloramphenicol

BHI agar + gentamicin

BHI agar + novobiocin

BHI agar + gentamicin and novobiocin
Frequency of conjugation

$$
\begin{aligned}
& 6.67 \times 10^{-4} \\
& 2.13 \times 10^{-3} \\
& 2.19 \times 10^{-5} \\
& 2.69 \times 10^{-4} \\
& 2.40 \times 10^{-3}
\end{aligned}
$$

\section{RESULTS}

\section{Characterization of the conjugation system}

In a typical experiment, the frequency of conjugation was $5.1 \times 10^{-4}$ (limits $4.8 \times 10^{-3}$ to $1 \cdot 1 \times 10^{-5}$ ). Variations to the procedure were tried to increase this frequency and to simplify the procedure. No transfer was detected in any experiment in which the donor and recipient were not filtered together. For example, no transconjugant colonies were found when $1.25 \times 10^{9}$ bacteria $\mathrm{ml}^{-1}$ of both donor and recipient were mixed and $0.15 \mathrm{ml}$ plated directly onto selective BHI agar. Similarly, no colonies grew when $75 \mu \mathrm{l}$ of donor and $75 \mu \mathrm{l}$ of the recipient (same concentrations) were pipetted onto the agar surface and then mixed. The effect of varying the density of bacteria was investigated. The same numbers of donor and recipient cells $\left(3.75 \times 10^{9}\right.$ of each) were mixed and filtered using filters of $491 \mathrm{~mm}^{2}$ or $1735 \mathrm{~mm}^{2}$ area. The frequency of transfer was almost four times higher when the smaller filter was used $\left(1.22 \times 10^{-3}\right.$ compared to $3.15 \times 10^{-4}$ ). The ratio of donor to recipient cells present prior to filter incubation was varied over a 15-fold range. An equal ratio of donor and recipient cells gave the highest frequency of conjugation.

In general, filter incubation on BHI agar plates seems to be the common procedure in the investigation of Staph. aureus transfer via filter matings (Schaberg et al., 1982; Archer \& Johnson, 1983; Forbes \& Schaberg, 1983; Goering \& Ruff, 1983). Although McDonnell et al. (1983) reported similar transfer frequencies whether nutrient agar or BHI agar plates were used, no-one has reported the effect of incubating the filter on selective agar plates. The effect of plating the filters on BHI agar plates containing various antibiotics was investigated. The results (Table 1) show that transfer occurred most readily on plates with the addition of either chloramphenicol or gentamicin plus novobiocin. Transfer was reduced in the presence of either gentamicin or novobiocin alone.

\section{Cloning BglII fragments from pJE1 into pCW59}

A restriction enzyme map of $\mathrm{pJE} 1$ was constructed (Fig. 1). In an attempt to isolate and clone the complete transfer region, plasmid pJE1 was digested to completion with $B g l \mathrm{II}$ and the fragments were cloned into pCW59. A total of 48 clones were obtained. The sizes of the cloned fragments in $\mathrm{kbp}$, with the number of clones obtained for each size shown in parentheses, were: $15.2(0) ; 15.0(0) ; 3.8(6) ; 3.5(6) ; 3.4(6) ; 2.7(9) ; 2.0(6) ; 1.5(9)$ and $1.4(6)$. The two largest fragments were not isolated from clones even after their purification from the smaller fragments by electrophoretic elution onto DEAE-cellulose paper prior to ligation.

Each clone was tested for its resistance to gentamicin and ethidium bromide. The former was located on the $3.5 \mathrm{kbp}$ fragment and the latter on the $2.0 \mathrm{kbp}$ fragment (Fig. 1).

A representative example of each of the seven different clones was tested for its ability to conjugate with Staph. aureus $\mathrm{B} 111 \mathrm{Nv}^{\mathrm{R}}$. $\mathrm{Tc}^{\mathrm{R}} \mathrm{Nv}^{\mathrm{R}}$ transconjugants were selected in each case but, in addition, for the clone conferring resistance to gentamicin, $\mathrm{Gm}^{\mathrm{R}} \mathrm{Nv}^{\mathrm{R}}$ transconjugants were selected. None of the clones gave transconjugants although the parental plasmid, pJE1, transferred at its normally high frequency $\left(5 \times 10^{-4}\right)$. 


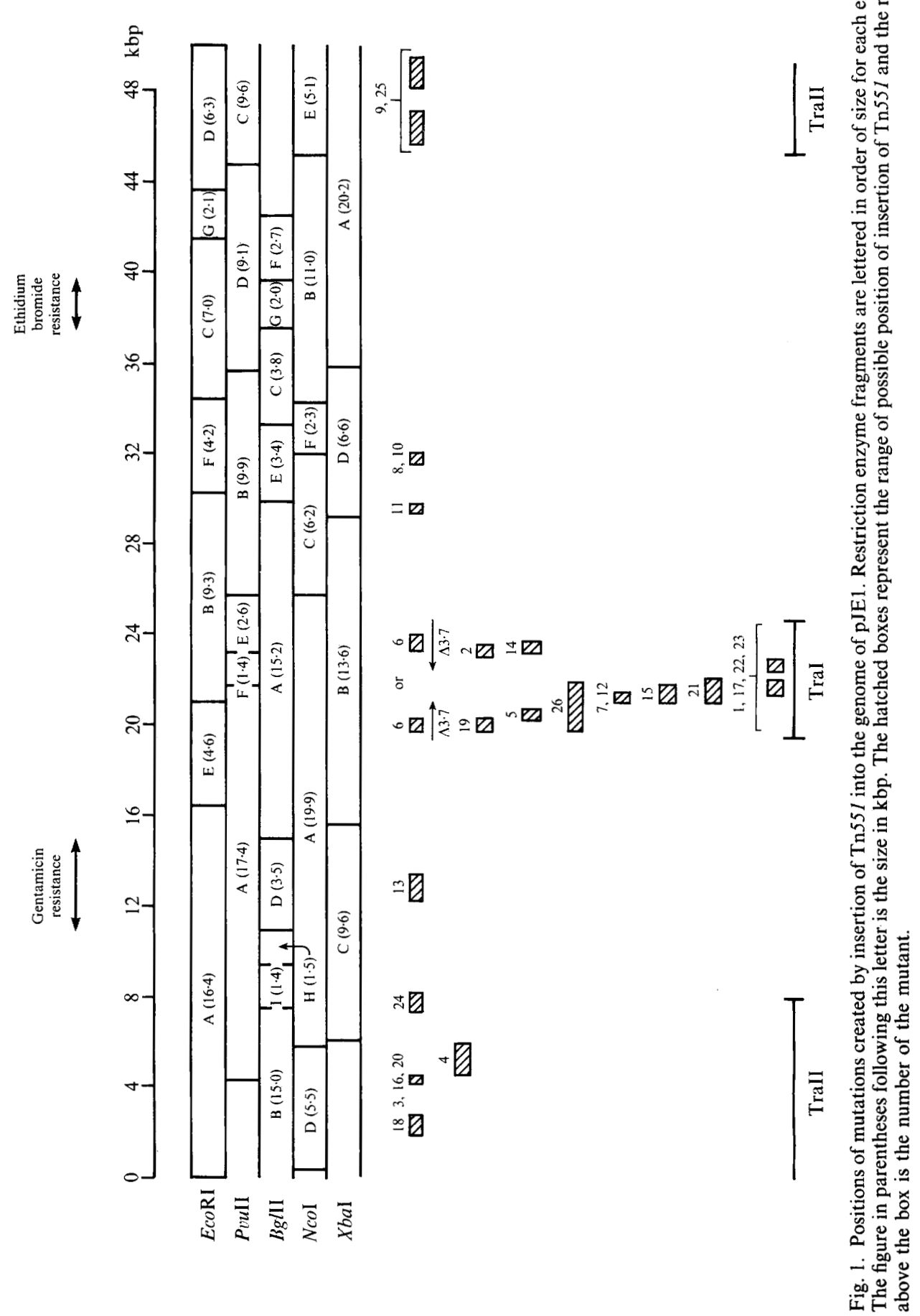


Table 2. Conjugation frequency of mutants of pJEl

$\begin{array}{cccc}\text { Mutant no. } & \begin{array}{c}\text { Ratio of } \\ \text { conjugation with pJE1/ } \\ \text { conjugation with mutant }\end{array} & \begin{array}{c}\text { Map position } \\ \text { of insert }\end{array} & \begin{array}{c}\text { Orientation } \\ \text { of transposon }\end{array} \\ 1-3 & \infty & 4 \cdot 4 & \text { B } \\ 1-16 & \infty & 4 \cdot 4 & \text { B } \\ 1-20 & \infty & 4 \cdot 4 & \text { B } \\ 1-4 & \infty & 5 \cdot 3 & \text { B } \\ 1-6 & \infty & 19 \cdot 9 & \text { B } \\ 1-21 & \infty & 21 \cdot 5 & \text { B } \\ 1-25 & \infty & 46 \cdot 4 & \text { A/B } \\ 1-9 & \infty & 48 \cdot 9 & \text { A/B } \\ 1-14 & 3000 & 23 \cdot 4 / 21 \cdot 9 & \text { A } \\ 1-17 & 750 & 22 \cdot 8 & \text { A/B } \\ 1-15 & 333 & 21 \cdot 2 & \text { B } \\ 1-26 & 229 & 20 \cdot 8 & \text { B } \\ 1-7 & 183 & 21 \cdot 2 / 21 \cdot 9 & \text { A } \\ 1-23 & 90 & 22 \cdot 8 & \text { A/B } \\ 1-18 & 76 & 2 \cdot 3 & \text { A } \\ 1-1 & 68 & 21 \cdot 9 / 22 \cdot 8 & \text { A/B } \\ 1-22 & 55 & 21 \cdot 9 / 22 \cdot 8 & \text { A/B } \\ 1-12 & 9 \cdot 3 & 21 \cdot 2 & \text { A } \\ 1-19 & 4 \cdot 7 & 20 \cdot 0 & \text { A } \\ 1-13 & 2 \cdot 0 & 13 \cdot 8 & \text { A } \\ 1-5 & 1 \cdot 5 & 20 \cdot 4 & \text { A } \\ 1-2 & 1 \cdot 2 & 23 \cdot 2 & \text { A } \\ 1-11 & 1 \cdot 2 & 29 \cdot 6 & \text { A } \\ 1-8 & 1 \cdot 0 & 31 \cdot 8 & \text { B } \\ 1-10 & 1 \cdot 0 & 31 \cdot 8 & \text { B } \\ 1-24 & 0 \cdot 3 & 7 \cdot 8 & \text { A } \\ & & & \end{array}$

Transposon mutagenesis as a method for locating parts of Staph. aureus plasmid DNA involved in transfer

Characterization of the mutants. Plasmid DNA was prepared from each of the 26 mutants. Digestion with restriction endonucleases $E c o$ RI and $P v u I I$ was used to identify the fragment into which the transposon had inserted. Tn551 was known to contain two $B g / \mathrm{II}$ sites and found to carry single $\mathrm{NcoI}$ and $\mathrm{XbaI}$ sites. The mapping of these two latter sites within Tn 551 allowed the position of the transposon within pJE1 to be mapped more precisely for each mutant. As Tn551 can insert in one of two possible orientations, and because some fragments were large, there were often four possible insertion sites. The results from EcoRI and PvuII digests were used, where possible, to discard any of the four possible sites derived from the digestions with other enzymes. The orientation of the transposon could be determined in all but six mutants. The most probable insertion position was determined on the basis of the positions which most closely correlated from each of the enzymes $B g I I I, N c o I$ and $X b a I$. The map position for each mutant (Fig. 1) is an average value and therefore a range is also given. The mutant plasmids were designated pJE1-1 to pJE1-26. The mutant pJE1-6 had a deletion of 3.7 kbp of pJE1 at the site of insertion of the Tn551.

Conjugation of the mutants. Conjugation was performed with each of the 26 mutants and the recipient $B 111 \mathrm{Nv}^{\mathrm{R}}$. A total of 11 batches of conjugations were performed and in each case the conjugation frequency between $8325\left(\mathrm{pJE} 1\right.$ ) and $\mathrm{B} 111 \mathrm{Nv}^{\mathrm{R}}$ was also determined. Results (Table 2) are expressed as the ratio of the control conjugation to the mutant conjugation.

The mutants were classified into five groups according to the level of conjugation: none (ratio $\infty$ ); very low (ratio 50-3000); low (ratio 4-10); normal (ratio 1-2) and high (ratio <1). Plasmid DNA was prepared from a transconjugant colony selected from each of the successful conjugations. This was digested with $B g I I I$ and compared with similarly digested parental mutant DNA to determine if exact transfer had occurred. The transfer of mutant plasmids occurred without detectable alterations of the DNA in all examples. 


\section{DISCUSSION}

The results indicate that direct cell-to-cell contact is an absolute requirement for plasmid transfer, strengthening the argument that the process is conjugation. Futher support for this is that increasing the density of cells on the filter increases the transfer frequency and that divergence from an equal ratio of donor to recipient cells decreases it : the greater the divergence, the lower the frequency.

The increase in the conjugation frequency upon the addition of gentamicin plus novobiocin to the incubation plates can be interpreted by postulating that in this case selection for early transconjugants occurs. The transconjugant cells divide and produce further doubly resistant progeny in the absence of competition from donor or recipient cells. Plating on singly selective plates (gentamicin or novobiocin) inhibits growth of either the donor or the recipient, resulting in an unequal ratio of donor and recipient cells and hence a lower transfer rate. The increase in the frequency of transfer when chloramphenicol is added to the incubation plates may be due to a different phenomenon, as this antibiotic will prevent cell growth in donor, recipient and transconjugants. Chloramphenicol is known, however, to increase the rate of cell wall synthesis (Mandelstam \& Rogers, 1958). By preferentially utilizing the cell's resources of amino acids, addition of chloramphenicol may increase the rate of cell wall synthesis after transfer has occurred via a transient protoplast formation between cells. Antibiotics may increase competence of the bacteria by preventing growth: this is being further investigated.

The inability to clone the complete transfer region is probably due to more than one transfer region being involved. This explanation was proved by analysing pJEl via transposon mutagenesis. The insertion points of Tn551 in the 26 mutants are not randomly distributed around the plasmid genome; the transposon has inserted into 'preferred sites' or 'hotspots'. One such region lies between 19.9 and 23.4 map units, within which the transposon has inserted 14 times. Although this area represents only $7 \%$ of the total genome, it contains $54 \%$ of the total insertions. A second 'preferred insertion area' appears between 2.3 and 7.8 map units, representing $11 \%$ of the genome, into which $23 \%$ of the insertions have occurred. There are no insertions, however, between 31.8 and 46.4 map units ( $29 \%$ of the genome) or between 13.3 and 19.9 map units ( $13 \%$ of the genome). Each mutant was created by an independent insertion of Tn551 into pJE1.

The clustering of Tn55I insertions into pJE1 is within the two regions involved in conjugation. Insertion of Tn551 into the area between map units 20 and 23 either abolished or considerably reduced the conjugation frequency. On the basis that this region is involved in conjugation it has been designated region 'Tral'. Another area of the genome into which insertions abolished conjugation and others considerably reduced it was between 45.7 and 6.0 map units $(10.3 \mathrm{kbp})$. This region has been designated 'TraII'. These regions are separated by areas in which insertions had no apparent effect on conjugation; the regions TraI and TraII are probably therefore separate operons. It cannot be excluded that more than two regions may be involved. The area designated TraII may be more than one operon, as mutants pJE1-9 and pJE1-25 are relatively well separated from mutants pJE1-3, pJE1-4, pJE1-16 and pJE1-20. It is interesting that Christie \& Dunny (1986) mapped nine distinct Tra regions within the Strep. faecalis plasmid pCF-10 (58 kbp).

The conjugation frequencies obtained with the 26 mutants were broadly classified into five classes. In eight mutants, transfer was abolished but in nine, transfer was extremely low and in two (pJE1-12 and pJE1-19) transfer was slightly higher but still greatly reduced compared with that of the parental plasmid. These insertions may be close to the boundary of the region involved in transfer and affect the transfer to varying extents, depending upon their distance from the operon. If the mapping is correct, one boundary of the TraI region can be placed between map units $23 \cdot 2$ and $23 \cdot 3$, as mutant pJE1-2 (map position $23 \cdot 2 \pm 0 \cdot 1$ ) resulted in a normal transfer frequency whilst mutant pJE1-14 (map position $23 \cdot 4 \pm 0 \cdot 2$ ) produced a very low transfer rate.

Mutant pJE1-5, which exhibited a normal conjugation phenotype had an insert within the Tral region between those of other mutants which showed greatly reduced conjugation 
frequency. The region designated TraI may actually consist of more than one operon or mutant pJE1-5 may have inserted into an intercistronic region.

Insertion of Tn55I into map position $7 \cdot 8 \pm 0 \cdot 4$ resulted in a mutant (pJE1-24) which gave an enhanced frequency of conjugation compared with the parental plasmid. In this example, Tn551 may have inserted into a control region for conjugation. Such a region would normally repress transfer; insertion into the gene(s) involved abolishes or reduces the control. Asch et al. (1984) also reported such a region on the self-transmissible Staph. aureus plasmid pCRG1600. Christie \& Dunny (1986) found six separate regions on the Strep. faecalis plasmid pCF-10, insertion into which led to enhanced levels of transfer. They found that cells carrying these mutant plasmids differed in colony morphology or growth in broth from cells carrying the parental plasmid. No such change was observed for Staph. aureus mutant pJE1-24. A second explanation is that Tn551 may not have inserted into a control region but was using a high-level promoter of its own to activate an operon of $\mathrm{pJEl}$ involved in the conjugal process.

Insertion of Tn55I at map position $19.9 \pm 0.3$ was accompanied by a deletion of about $3.7 \mathrm{kbp}$ of $\mathrm{pJE} 1$. Although deletions are known to be a consequence of the excision of transposons, it is unusual for them to occur on insertion (Novick et al., 1979). The insertion of Tn551 into pJE1 reported here appears to be one such example. It is possible that pJE1 normally carries a transposon of $3.7 \mathrm{kbp}$ within this region. The ends of this transposon may have homology with those of Tn551 making them recombinogenic. In the case of mutant pJE1-6, a recombination event between the two transposons may have caused the insertion of Tn551 accompanied by deletion of the original transposon.

J.E. was a recipient of an SERC Studentship for training in research methods.

\section{REFERENCES}

ARChER, G. L. \& Johnston, J. L. (1983). Selftransmissible plasmids in staphylococci that encode resistance to aminoglycosides. Antimicrobial Agents and Chemotherapy 24, 70-77.

Asch, D. K., Goering, R. V. \& Ruff, E. A. (1984). Isolation and preliminary characterization of a plasmid mutant derepressed for conjugal transfer in Staphylococcus aureus. Plasmid 12, 197-202.

Browne, C. (1985). Plasmid-chromosomal interactions in Staphylococcus aureus. DPhil thesis, University of Oxford.

CHRISTIE, P. J. \& DunNY, G. M. (1986). Identification of regions of the Streptococcus faecalis plasmid pCF10 that encode antibiotic resistance and pheromone response functions. Plasmid 15, 230-241.

Clewell, D. B., AN, F. Y., White, B. A. \& GawronBurke, C. (1985). Streptococcus faecalis sex pheromone (cAM373) also produced by Staphylococcus aureus and identification of a conjugative transposon (Tn918). Journal of Bacteriology 162, 1212-1220.

Dretzen, G., Bellard, M., Sassone-Corse, P. \& Chambon, P. (1981). A reliable method for the recovery of DNA fragments from agarose and acrylamide gels. Analytical Biochemistry 112, 295298.

Engel, H. W. B., Soedirman, N., Rost, J. A., van LeEuWen, W. J. \& VAN Embden, J. D. A. (1980). Transferability of macrolide, lincomycin and streptogramin resistances between group A, B and D streptococci, Streptococcus pneumoniae and Staphylococcus aureus. Journal of Bacteriology 142, 407-413.

Evans, J. (1986). The conjugation system of Staphylococcus aureus. DPhil thesis, University of Oxford.
Forbes, B. A. \& SCHABERG, D. R. (1983). Transfer of resistance plasmids from Staphylococcus epidermidis to Staphylococcus aureus: evidence for conjugative exchange of resistance. Journal of Bacteriology 153, 627-634.

Goering, R. V. \& Ruff, E. A. (1983). Comparative analysis of conjugative plasmids mediating gentamicin resistance in Staphylococcus aureus. Antimicrobial Agents and Chemotherapy 24, 450-452.

Khan, S. A. \& Novick, R. P. (1980). Terminal nucleotide sequences of Tn 551 , a transposon specifying erythromycin resistance in Staphylococcus aureus: homology with Tn3. Plasmid 4, 148-154.

LACEY, R. W. (1980). Evidence for two mechanisms of plasmid transfer in mixed cultures of Staphylococcus aureus. Journal of General Microbiology 119, 423-435.

LINDBERG, M. (1981). Genetic studies in Staphylococcus aureus using protoplasts : cell fusion and transformation. In Staphylococci and Staphylococcal Infections, Zentrablatt für Bakteriologie, Mikrobiologie und Hygiene supplement 10 , edited by J. Jeljaszewicz, pp. 535-540. Berlin: Gustav Fischer Verlag.

Mandelstam, J. \& Rogers, H. J. (1958). Chloramphenicol-resistant incorporation of amino acids into staphylococci and cell-wall synthesis. Nature, London 181, 956-957.

McDonnell, R. W., Sweeney, H. M. \& Cohen, S. (1983). Conjugational transfer of gentamicin resistance in Staphylococcus aureus and Staphylococcus epidermidis. Antimicrobial Agents and Chemotherapy 23, $151-160$.

Naidoo, J., Noble, W. C., Weissmann, A. \& Dyke, K. G. H.(1983). Gentamicin-resistant staphylococci: 
genetics of an outbreak in a dermatology department. Journal of Hygiene 91, 7-16.

Novick, R. P. \& BouanCHAUd, D. (1971). Extrachromosomal nature of drug resistance in Staphylococcus aureus. Annals of the New York Academy of Sciences 182, 279-294.

Novick, R. P., Edelman, I., Latta, P. D., Swanson, E. C. \& PATtee, P. A. (1979). Translocatable elements in Staphylococcus aureus. Contributions to Microbiology and Immunology 6, 41-55.
Schaberg, D. R., Clewell, D. B. \& Glatzer, L. (1982). Conjugative transfer of R-plasmids from Streptococcus faecalis to Staphylococcus aureus. Antimicrobial Agents and Chemotherapy 22, 204-207.

Wilson, C. R., Skinner, S. E. \& SHAw, W. V. (1981). Analysis of two chloramphenicol resistance plasmids from Staphylococcus aureus: insertional inactivation of $\mathrm{Cm}$ resistance, mapping of restriction sites and construction of cloning vehicles. Plasmid 5, 245-258. 